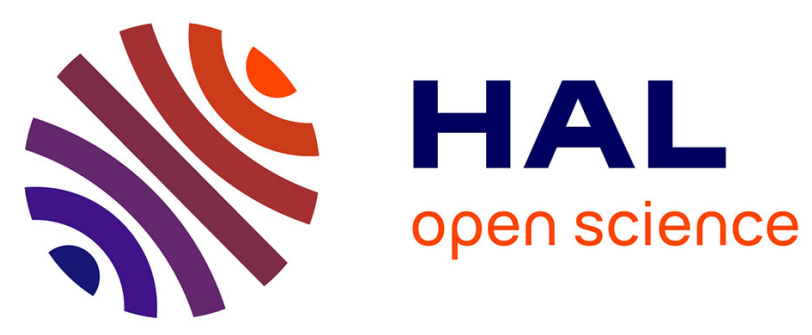

\title{
Aromatic Xanthates and Dithiocarbamates for the Polymerization of Ethylene through Reversible Addition-Fragmentation Chain Transfer (RAFT)
}

Arne Wolpers, Cédric Bergerbit, Bastian Ebeling, Franck d'Agosto, Vincent

Monteil

\section{To cite this version:}

Arne Wolpers, Cédric Bergerbit, Bastian Ebeling, Franck d'Agosto, Vincent Monteil. Aromatic Xanthates and Dithiocarbamates for the Polymerization of Ethylene through Reversible AdditionFragmentation Chain Transfer (RAFT). Angewandte Chemie International Edition, 2019, 58 (40), pp.14295-14302. 10.1002/anie.201905629 . hal-02316556

\section{HAL Id: hal-02316556 \\ https://hal.science/hal-02316556}

Submitted on 24 Nov 2020

HAL is a multi-disciplinary open access archive for the deposit and dissemination of scientific research documents, whether they are published or not. The documents may come from teaching and research institutions in France or abroad, or from public or private research centers.
L'archive ouverte pluridisciplinaire HAL, est destinée au dépôt et à la diffusion de documents scientifiques de niveau recherche, publiés ou non, émanant des établissements d'enseignement et de recherche français ou étrangers, des laboratoires publics ou privés. 


\title{
Aromatic xanthates and dithiocarbamates for the polymerization of ethylene through reversible addition-fragmentation chain transfer (RAFT)
}

\author{
Arne Wolpers, Cédric Bergerbit, Bastian Ebeling, Franck D’Agosto, ${ }^{*}$ Vincent Monteil ${ }^{\star}$
}

\begin{abstract}
Aromatic xanthates and dithiocarbamates were used as chain-transfer agents (CTAs) in reversible addition-fragmentation chain transfer (RAFT) polymerizations of ethylene under rather mild conditions $\left(\leq 80^{\circ} \mathrm{C}, \leq 200\right.$ bar). While detrimental side fragmentation of the intermediate radical leading to a loss of living chain-ends was observed in a previous study of alkyl xanthate CTAs, this mechanism was absent for the aromatic CTAs. The loss of living chain-ends was nevertheless detected for the aromatic xanthates via a different mechanism based on cross-termination. Narrow molar-mass distributions with dispersities between 1.2 and 1.3 were still obtained up to number average molar masses $M_{\mathrm{n}}$ of $1000 \mathrm{~g} \mathrm{~mol}^{-1}$. In contrast, the loss of chain-ends was minor for dithiocarbamates, yielding polyethylene up to $M_{\mathrm{n}}=3000 \mathrm{~g} \mathrm{~mol}^{-1}$ with dispersities between 1.4 and 1.8. While all systems investigated showed significant rate retardation, the dithiocarbamates are indeed the first CTAs giving polyethylene with a high livingness via RAFT polymerization, which finally offers the possibility to readily synthesize various new polyethylene-based polymer architectures.
\end{abstract}

\section{Introduction}

Reversible deactivation radical polymerization $(\mathrm{RDRP})^{[1]}$ is a mature technology that has been extensively studied for almost twenty-five years. ${ }^{[2,3]}$ The vast majority of monomers polymerizable via a conventional free radical mechanism have been successfully used in RDRP, leading to a myriad of new polymer architectures and properties. However, the RDRP of some monomers, including several monomers of major industrial importance, ${ }^{[4-6]}$ remains challenging. Ethylene, which leads to polyethylene (PE), the most-produced polymer worldwide, is one such monomer. Ethylene is gaseous under ambient conditions and requires specific expertise for its polymerization in autoclaves. With a critical point at 50.4 bar and $9.2^{\circ} \mathrm{C}$, ethylene becomes a supercritical fluid above these conditions. Polymerization therefore takes place in a more complex medium than for most conventional liquid monomers. ${ }^{[7]}$ In addition, propagating polyethylenyl radicals (PE*) are very reactive. Generating this reactive species through homolytic bond cleavage is difficult, which rules out RDRP techniques based on reversible termination

\footnotetext{
Dr. A. Wolpers, C. Bergerbit, Dr. B. Ebeling, Dr. F. D’Agosto, Dr. V. Monteil Université de Lyon, Université Lyon 1, CPE Lyon, CNRS UMR 5265 , Laboratoire C2P2, Équipe LCPP, 69616 Villeurbanne, CEDEX, France E-mail: vincent.monteil@univ-lyon1.fr franck.dagosto@univ-lyon1.fr
}

Supporting information for this article is given via a link at the end of the document. (e.g., nitroxide-mediated polymerization ${ }^{[8]}$ or atom-transfer radical polymerization ${ }^{[9,10]}$. Techniques based on degenerative chaintransfer (DT), on the other hand, offer more promise for controlling ethylene polymerization. ${ }^{[11,12]}$ We recently showed the first successful reversible addition-fragmentation chain transfer (RAFT) polymerization of ethylene using alkyl xanthates ${ }^{[13]}$ and organotellurium-mediated radical polymerization (TERP) of ethylene ${ }^{[14]}$ under rather mild (for ethylene) polymerization conditions $\left(200 \mathrm{bar}, 70^{\circ} \mathrm{C}\right) .[15,16]$

Scheme 1. (a) Pre-equilibrium and main equilibrium in RAFT ${ }^{[13]}$ and (b) main equilibrium in TERP ${ }^{[14]}$ with the respectively observed side fragmentation for ethylene polymerizations. P, P', and P" represent polymer chains.

(a) Reversible chain transfer in RAFT polymerization (pre-equilibrium):

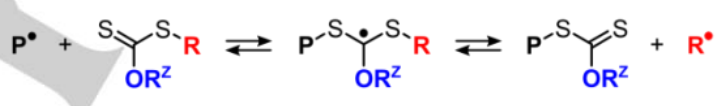

Degenerative chain transfer (DT) in RAFT polymerization (main equilibrium):

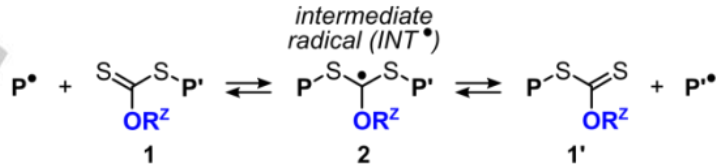

$$
\begin{aligned}
& \text { for } Z \text { group } \\
& \mathrm{OR}^{\mathrm{Z}}=\mathrm{OEt}, \mathrm{OCH}_{3}
\end{aligned}
$$

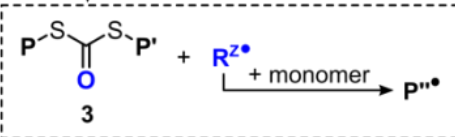

(b) Degenerative chain transfer (DT) in TERP (main equilibrium):

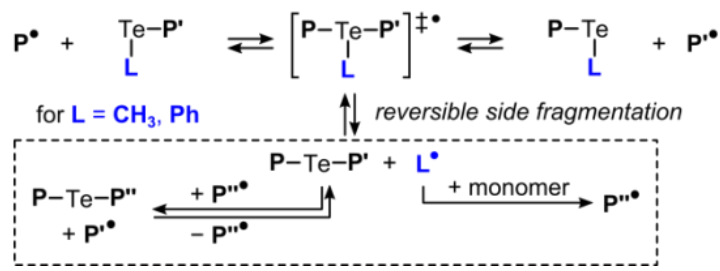

Although the investigated RAFT system demonstrated controlled chain growth (with molar masses of PE increasing linearly with increasing ethylene conversion), a distinct side reaction, identified as side fragmentation, could be observed (see Scheme 1a). ${ }^{[17]}$ In side fragmentation, the intermediate radical (INT*) 2 fragments to give radical $R^{\mathrm{Z} \cdot}$ and polymer $\mathbf{3}$, where polymer 3 features two chains bound by one dithiocarbonate $\mathrm{SC}(=\mathrm{O}) \mathrm{S}$ bridge. (While the same reaction can occur in the pre- 
equilibrium, it is omitted for clarity in Scheme 1a.) This side reaction is caused by the rather low stability of the propagating $\mathrm{PE}$; promoting side fragmentation as a competitive reaction to $\mathrm{DT}$ and releasing a similarly unstable alkyl radical $R^{z}$. As the $C=O$ double bond in $\mathbf{3}$ is much less reactive toward radical addition than the $\mathrm{C}=\mathrm{S}$ double bond in $\mathbf{1}$ or $\mathbf{1}$ ', $\mathbf{3}$ is virtually dead and accumulates in the system. This not only diminishes chain-growth control but also incessantly reduces the amount of living and endfunctionalized chains. To the best of our knowledge, the described RAFT system was the first one where side fragmentation could be observed experimentally, while side fragmentation had been predicted earlier by a theoretical study of RAFT polymerizations of vinyl acetate (VAc). ${ }^{[18]}$

In our earlier work, ${ }^{[13]}$ we showed that a chain-transfer agent (CTA) with $\mathrm{Z}=\mathrm{OCH}_{3}$ (5 in Chart 1) leads to less (yet still pronounced) side fragmentation than one with $Z=$ OEt (4). The ${ }^{\circ} \mathrm{CH}_{3}$ species is less stable than $\mathrm{Et}^{\cdot}$ and its formation through side fragmentation is therefore less favoured. One study reported ethylene (co)polymerization using $\mathbf{5}$ without addressing side fragmentation. ${ }^{[19]}$ In TERP of ethylene, we detected a comparable side-fragmentation mechanism that has never been observed for any other monomer type either (see Scheme 1b). ${ }^{[14]}$ This reaction is reversible, so no dead chains are generated, but molar-mass control is still reduced because the formed PE-Te-PE species undergoes slower chain transfer and has roughly twice the molar mass of the PE-Te-L species of the DT (with $L$ being the stabilizing group). The side reaction could be virtually eliminated when $\mathrm{L}$ was changed from $\mathrm{CH}_{3}$ to a $\mathrm{Ph}$ group, since the $\mathrm{Ph}$ group is even less prone to fragmentation.

In the present publication, we apply this rather straightforward strategy to suppress side fragmentation in the RAFT polymerization of ethylene. We advance from the previouslystudied alkyl xanthates $\mathbf{4}$ and $\mathbf{5}$ to the aromatic xanthates and dithiocarbamates 6-12 and investigate their potential as effective CTAs for RAFT polymerization of ethylene.

\section{Experimental Section}

The experimental setup and conditions used for the polymerization of ethylene are similar to those used in our previous studies, ${ }^{[13,14]}$ and briefly described in the following. In a typical procedure, the radical initiator 2,2' azobis(2-methylpropionitrile) (AIBN) and the CTA were stirred in $50 \mathrm{~mL}$ of dimethyl carbonate (DMC) in a $160 \mathrm{~mL}$ autoclave reactor at either $70^{\circ} \mathrm{C}$ or $80^{\circ} \mathrm{C}$, and at a constant ethylene pressure between 60 bar and 200 bar. In a limited number of runs, an autoclave with a sapphire window was used in the same conditions, and it was observed that upon polymerization, the formation of insoluble PE rendered the initially clear solution turbid. After a predetermined polymerization time, the reactor was cooled down, opened, and the contents were collected with toluene. Ethylene conversion was determined gravimetrically. The polymer was analyzed via size-exclusion chromatography (SEC, in 1,2,4-trichlorobenzene at $150{ }^{\circ} \mathrm{C}$, conventional calibration with linear PE) to determine its molar-mass distribution (MMD) and via NMR spectroscopy (in benzene- $d_{6} /$ tetrachloroethene, $1: 2$ by volume, at $90^{\circ} \mathrm{C}$ ). The materials used, experimental setup, polymerization procedure, and analytical methods are described in more detail in the Supporting Information. ${ }^{[20-22]}$
Chart 1. CTAs for RAFT polymerizations of ethylene used in our earlier work ${ }^{[13]}$ $(4,5)$ and in the present one $(4,6-12)$.

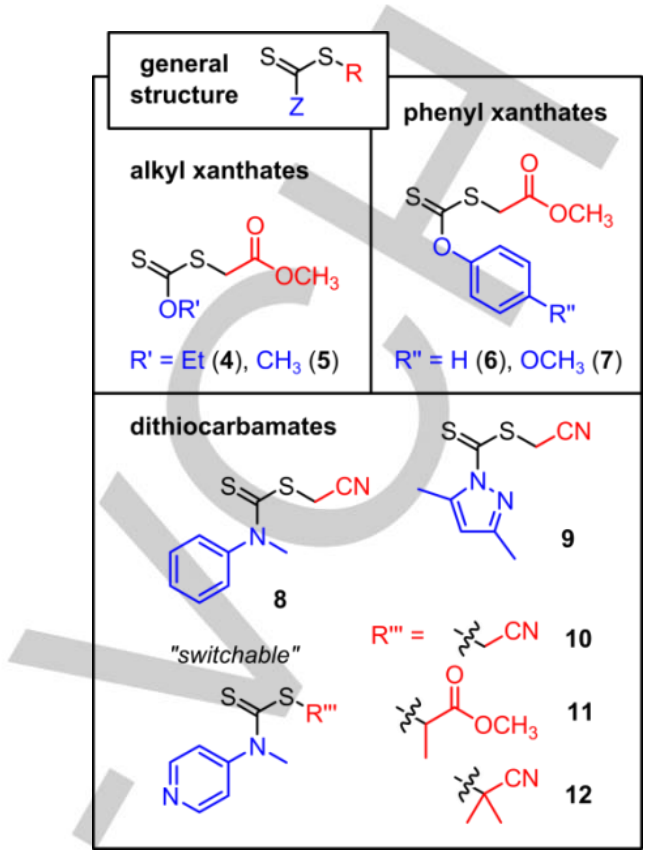

\section{Results and Discussion}

Xanthates and dithiocarbamates are known to destabilize INT ${ }^{\cdot[23,24]}$ (Scheme 1a) and are thus ideal for the polymerization of less-activated monomers (LAMs) like ethylene or VAc. Especially attractive are the so-called "switchable" agents 10-12 since postor pre-protonation of the $\mathrm{N}$ atom in the pyridyl ring significantly increases the stabilization of INT' and would thus additionally allow the polymerization of more-activated monomers (MAMs) like styrene or (meth)acrylates. ${ }^{[25]} 9$ was recently reported to control the chain growth in polymerizations of VAc and was thus evaluated as well.[26]

\section{Polymerizations with $\mathrm{O}$-aromatic xanthates}

Polymerizations were conducted at $70{ }^{\circ} \mathrm{C}$ and 200 bar of ethylene using $50 \mathrm{mg}$ of AIBN $\left(6.09 \mathrm{mmol} \mathrm{L}^{-1}\right)$ and the xanthate CTAs 4, 6, or $7\left(18.3 \mathrm{mmol} \mathrm{L}^{-1}\right.$, with a concentration ratio [CTA]:[AIBN] of $3: 1)$. We decreased the concentration of CTA compared to our previous work on $\mathbf{4}$ and $\mathbf{5}$, in which we used [CTA]:[AIBN] = 10:1 and $50 \mathrm{mg}$ of AIBN. ${ }^{[13]}$ All aromatic xanthates $(6,7)$ and dithiocarbamates (8-12) resulted in retardation, and acceptable polymerization rates could only be attained by reducing their concentrations. Figure 1a shows the ethylene conversion versus polymerization time for the respective xanthate systems in comparison to a conventional polymerization system with no CTA. 
(a)

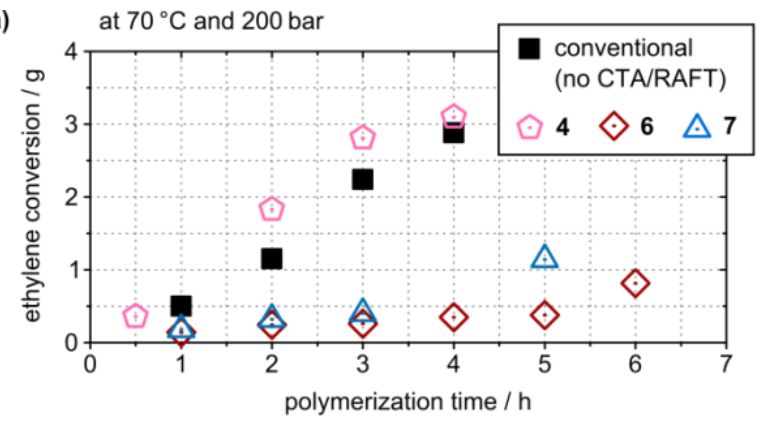

(b)

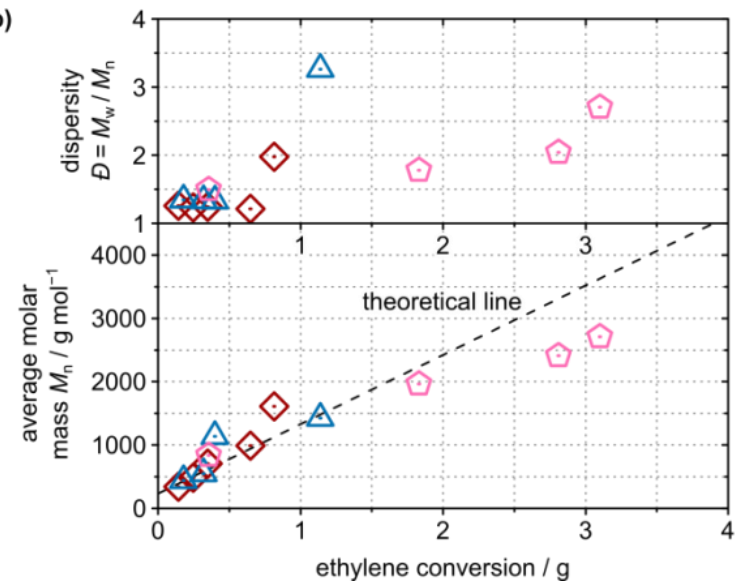

Figure 1. (a) Ethylene conversion versus polymerization time for RAFT systems with xanthates $\mathbf{4}, \mathbf{6}$, and $\mathbf{7}$ in comparison to the conventional radical polymerization system without a CTA and (b) the corresponding molar-mass evolutions. The conventional radical polymerization system yielded PE with $M_{n}$ values between 8000 and $13000 \mathrm{~g} \mathrm{~mol}^{-1}$ and $\Theta$ values between 2.0 and 3.7 .

Consistent with our earlier work, the use of the alkyl xanthate 4 did not lead to retardation compared to the conventional system. It even slightly increases the polymerization rate, a behavior rather atypical for RAFT systems. This might stem from a small impact of $\mathbf{4}$ on the polarity of the medium, as we have already shown that the yield of PE strongly depends on the polarity of the solvent used in the polymerization. ${ }^{[15]}$ In contrast to 4 , the aromatic xanthates $\mathbf{6}$ and 7 drastically decrease the polymerization rate to an extent that appears to be too great to be caused by polarity effects alone. Retardation might be caused by the expected strong stabilization of INT' in the RAFT equilibrium by the aromatic Z-groups, reducing the amount of $P E^{\cdot}{ }^{[20]}$ In addition, retardation might be a result of the impact of the respective Z-groups on the reduction of side fragmentation, ${ }^{[22]}$ which will be explained below.

As in our earlier work, the system with $\mathbf{4}$ showed very pronounced side fragmentation and formation of species 3 . Figure $2 \mathrm{a}$ shows a ${ }^{1} \mathrm{H}$ NMR spectrum of PE obtained with $\mathbf{4}$ after $2 \mathrm{~h}$ of polymerization. The formation of the side-fragmentation product can be quantified by the signal of the protons $h$ neighboring the $\mathrm{SC}(=\mathrm{O}) \mathrm{S}$ unit in relation to the protons $\mathrm{c}$ neighboring the living xanthate unit. $33 \%$ of the living chains were transformed into species 3 after $1.9 \mathrm{~g}$ of ethylene conversion $(2 \mathrm{~h}$

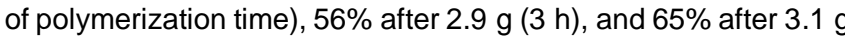
$(4 \mathrm{~h})$. Another ${ }^{1} \mathrm{H}$ NMR spectrum of PE obtained with 7 after $5 \mathrm{~h}$ of polymerization is shown in Figure $2 \mathrm{~b}$. While the Z-group of $\mathbf{7}$ is different from 4, and thus the shift of the signal of the protons $m$ slightly differs from c (cf. Figure 2a), the shifts of the signals of the protons from the identical (re)initiating group do not change $(\mathrm{o} / \mathrm{p} / \mathrm{q}=\mathrm{e} / \mathrm{f} / \mathrm{g})$. Upon side fragmentation, PE derived from both $\mathbf{4}$ and 7-and any other xanthate for that matter-loses its distinguishing $\mathrm{R}^{\mathrm{z}}$-group, leading to the same product of two chains being connected by one $\mathrm{SC}(=\mathrm{O}) \mathrm{S}$ bridge. However, in the spectrum in Figure $2 b$, no signal of the characteristic proton $h$ is observed. This observation applies to all PEs synthesized with either $\mathbf{6}$ or $\mathbf{7}$ in the entire publication, indicating that indeed no significant side fragmentation takes places in case of a phenylic leaving group.

While a pronounced stabilization of INT ${ }^{\cdot}$ by the Z-groups of 6 and 7 can cause retardation, the lack of side fragmentation might be another crucial reason for the rather low polymerization rates. As a general characteristic of RAFT polymerization, INT' is usually not active enough to (re)initiate a significant amount of new chains. For systems with $\mathbf{4}$ or $\mathbf{5}$, side fragmentation, along with the normal fragmentation in the RAFT equilibrium, generates a radical that can effectively (re)initiate polymerization. However, the side fragmentation mechanism does not exist for either 6 or $\mathbf{7}$. The average lifetime of INT is thus expected to be longer, which could slow down polymerization. A longer lifetime of INT' might also explain another feature observed in the systems with 6 or 7 : the systematic increase of signals in the ${ }^{1} \mathrm{H}$ NMR spectrum between $2.3 \mathrm{ppm}$ and $2.8 \mathrm{ppm}$, as well as in the aromatic region, accompanied by the decrease of all signals stemming from protons close to the $\mathrm{CS}_{2}$ end-group ( $\mathrm{j}-\mathrm{n}$ for $\mathbf{7}$ in Figure $2 \mathrm{~b}$ ). This indicates that the $\mathrm{CS}_{2}$ end-group is indeed consumed and chainend functionality is lost, even if it does not happen through side fragmentation. The extent of loss of chain-end functionality over ethylene conversion increases similarly to that observed for $\mathbf{4}$, with $32 \%$ after $0.8 \mathrm{~g}$ of ethylene conversion for 6 (after $6 \mathrm{~h}$ of polymerization) and $23 \%$ after $1.1 \mathrm{~g}$ for 7 (after $5 \mathrm{~h}$ ), which was determined from the $\mathrm{CH}_{2}$ protons neighboring the $\mathrm{CS}_{2}$ unit and the R-group (cf. $m$ and $p$ in Figure $2 b$ ). While the exact reaction mechanisms are still unclear, the observed NMR signals might partly stem from reaction products following cross-termination between $\mathrm{PE}^{\circ}$ and INT'. This reaction is expected to be particularly pronounced for rather long lifetimes and thus higher concentrations of INT'. As our reasoning on this matter is somewhat lengthy and should not become the main point of this publication, it is more thoroughly described in the Supporting Information. ${ }^{[27-34]}$

Figure $1 \mathrm{~b}$ shows the dispersity, $\oplus$, and average molar-mass values, $M_{n}$, from the polymerization systems discussed so far. While the conventional system gave high and constant $M_{\mathrm{n}}$ values early in the process (between 8000 and $13000 \mathrm{~g} \mathrm{~mol}^{-1}$ with $\Theta$ from 2.0 to 3.7, data not shown), all $M_{\mathrm{n}}$ values of the RAFT systems increase linearly with increasing ethylene conversion, which is theoretically expected in an RDRP. 


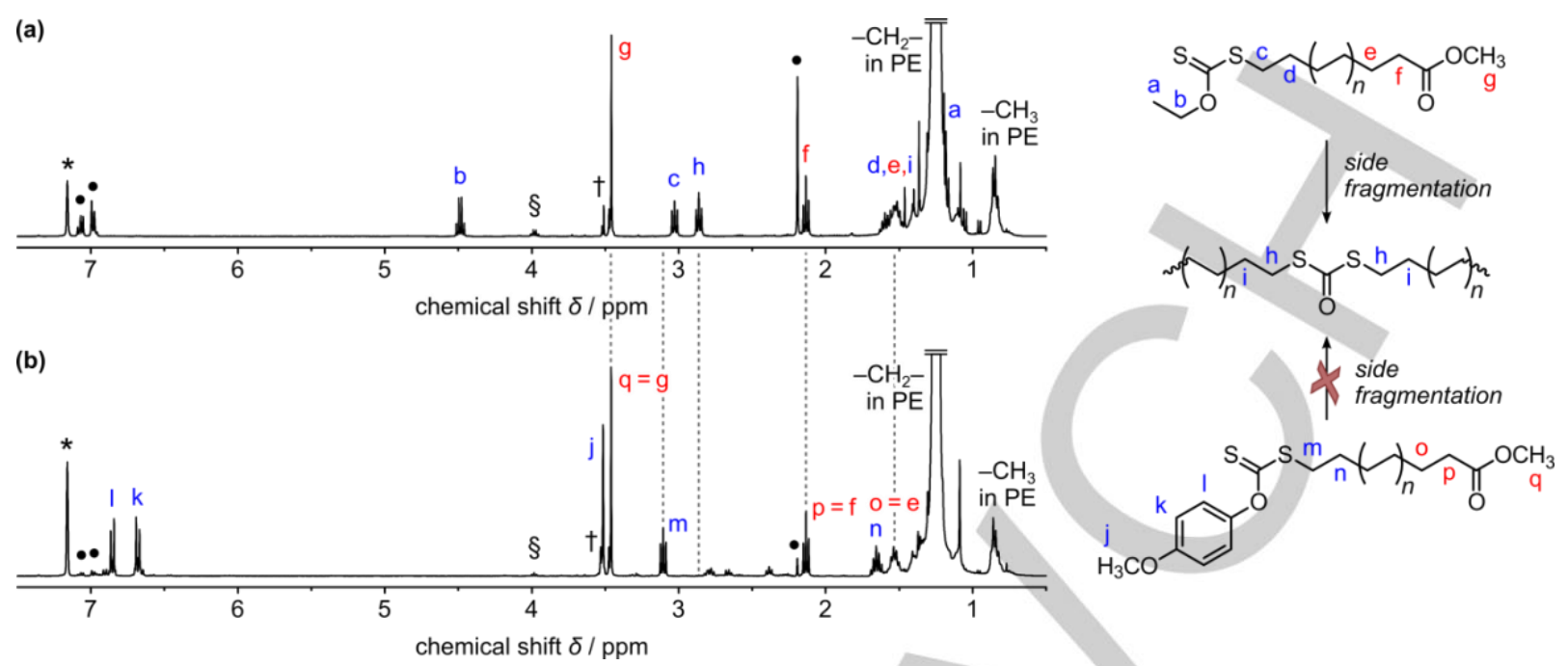

Figure 2. ${ }^{1} \mathrm{H}$ NMR spectra of PE synthesized in the presence of (a) 4 (cf. Figure 1, after $2 \mathrm{~h}$ ) and of (b) 7 (after $5 \mathrm{~h}$ ). The end group - $\mathrm{CH}_{3}$ stems either from intramolecular chain transfer inherent in ethylene radical polymerization or from (re)initiation of polymerization in case of side fragmentation for 4 . *NMR solvent benzene, "polymerization solvent DMC, stransfer to DMC, "collecting solvent toluene.

The MMDs of PE from 4 are unimodal and broaden from $D$ of about 1.5 to 2.2 , reaching $M_{\mathrm{n}} \approx 3000 \mathrm{~g} \mathrm{~mol}^{-1}$. For 6 and 7 , the MMDs are remarkably narrow at the beginning of the polymerization with $\Theta$ values as low as 1.2 for $M_{\mathrm{n}} \leq 1000 \mathrm{~g} \mathrm{~mol}^{-1}$, indicating the beneficial impact of the aromatic Z-groups on chaingrowth control. For $M_{\mathrm{n}}>1000 \mathrm{~g} \mathrm{~mol}^{-1}$, however, the MMDs broaden due to the evolution of a peak at high molar masses, which leads to a drastic increase of $\bigoplus$. Figure 3 shows the MMDs for 6 from $1 \mathrm{~h}$ to $6 \mathrm{~h}$ (similar MMDs could be observed for 7 ). While they are narrow and shifting to higher molar masses, the appearance of a second distribution can be seen after $6 \mathrm{~h}$. It is likely that this high-molar-mass peak originates from a conventional radical polymerization of ethylene, which will be explained below.

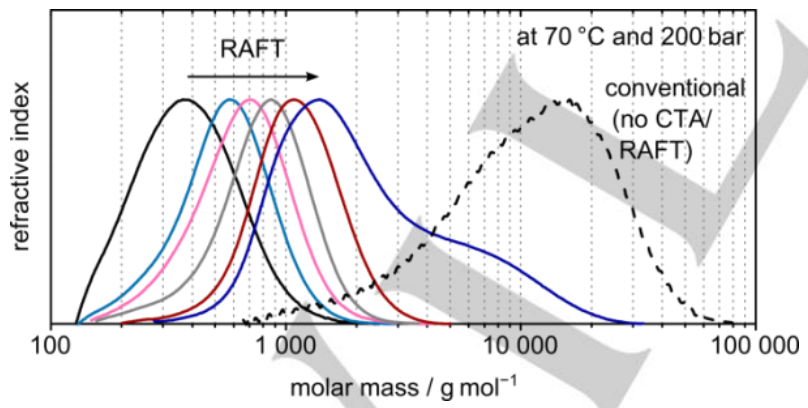

Figure 3. MMDs of PE produced in a conventional system (no CTA/RAFT) after $1 \mathrm{~h}$ and in the presence of 6 after 1,2, 3, 4, 5, and $6 \mathrm{~h}$. At $6 \mathrm{~h}$, the appearance of a high molar-mass species can be observed.

In order to increase the polymer yield, polymerizations were also conducted at $80^{\circ} \mathrm{C}$ instead of $70^{\circ} \mathrm{C}$ under otherwise identical conditions. The ethylene conversion versus time and the molar-mass evolution of polymerizations with 6 and 7 are presented in Figure 4 (series " $80^{\circ} \mathrm{C}, 200$ bar").

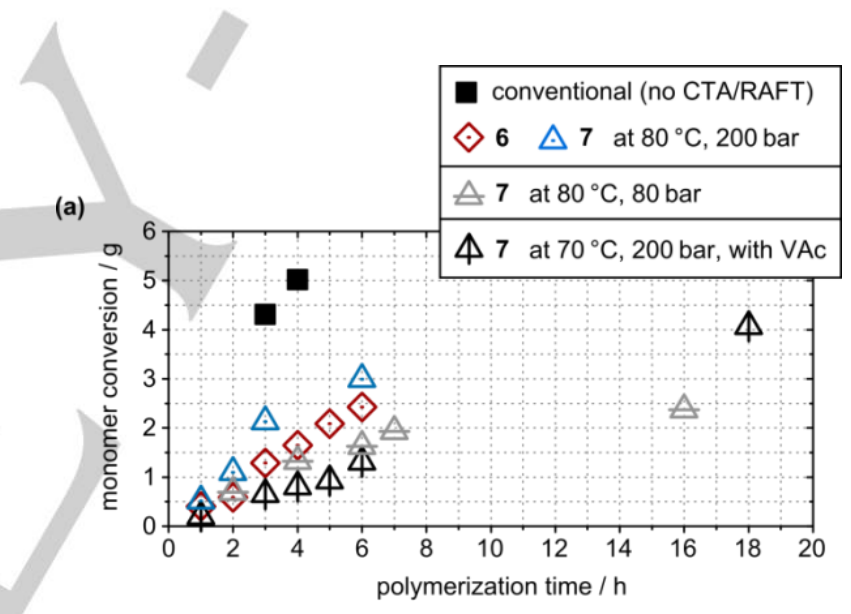

(b)

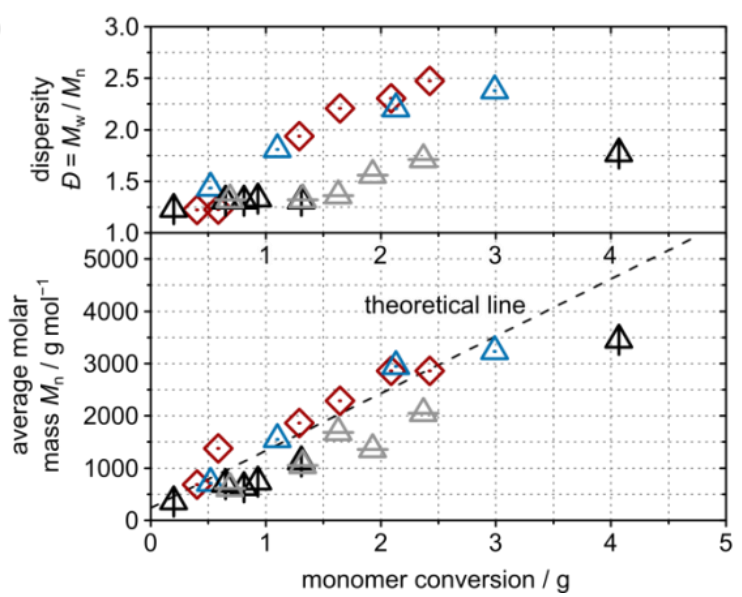

Figure 4. (a) Monomer conversion versus polymerization time for RAFT systems with xanthates 6 and 7 in comparison to the conventional radical polymerization system without a CTA and (b) corresponding molar-mass evolutions. Polymerization temperature and ethylene pressure as indicated. For polymerizations without VAc: monomer conversion = ethylene conversion, for polymerizations with VAc: monomer conversion = conversion of both ethylene and VAc. 
All effects described for $70^{\circ} \mathrm{C}$ were also observed for $80^{\circ} \mathrm{C}$, while the most significant difference was simply the expected higher PE yields. As for $70{ }^{\circ} \mathrm{C}$, systems with $\mathbf{6}$ and $\mathbf{7}$ exhibit low $\oslash$ values at the beginning of the polymerization that increase after $M_{\mathrm{n}}=1000 \mathrm{~g} \mathrm{~mol}^{-1}$ due to the evolution of a high-molar-mass species-the MMDs for 6 are shown in Figure S1.

The high-molar-mass peak arguably stems from a conventional polymerization, i.e., a polymerization without significant participation of RAFT. The peak closely matches the MMD obtained from the CTA-free conventional polymerization of ethylene (see Figure 3). As PE yields increase, this peak stays at similar molar masses and only increases in intensity, while the RAFT peak ceases to shift toward higher molar masses (Figure S1). Furthermore, while the polymerization is very slow for 6 and 7 at $70{ }^{\circ} \mathrm{C}$, the polymerization rate increases after the first appearance of the high-molar-mass species (last respective data point of both series in Figure 1a), supporting a non-RAFT mechanism.

The reason the RAFT mechanism is no longer significant could lie in the dispersion behavior of the polymer. In experiments that were carried out in a reactor with a sapphire window, we could see that for $50 \mathrm{~mL}$ of pure DMC as the solvent, the system remained phase-separated (bottom phase: DMC with dissolved ethylene; top phase: supercritical ethylene) up to ethylene pressures of about 95 bar. At higher pressures, the system turned into a single supercritical DMC/ethylene phase, as expected from thermodynamic calculations. ${ }^{[7]}$ When polymerizations with 7 were carried out at pressures lower than 95 bar, namely at 80 bar (see Figure 4, series " $80^{\circ} \mathrm{C}, 80$ bar" compared to series " $80^{\circ} \mathrm{C}$, 200 bar"), MMDs stayed unimodal during the polymerization up to molar masses of about $2000 \mathrm{~g} \mathrm{~mol}^{-1}$, far from the MMD of the respective conventional polymerization system (see Figure 5). The two-phase system at lower pressure $\left(80^{\circ} \mathrm{C}, 80\right.$ bar) thus showed better control than the comparable supercritical system $\left(80^{\circ} \mathrm{C}, 200 \mathrm{bar}\right)$. To further explore the connection between the state of the system employing 7 and its chain-growth control, we increased the pressure of a polymerization from originally 80 bar (two phases) to 120 bar (supercritical) within a few seconds.

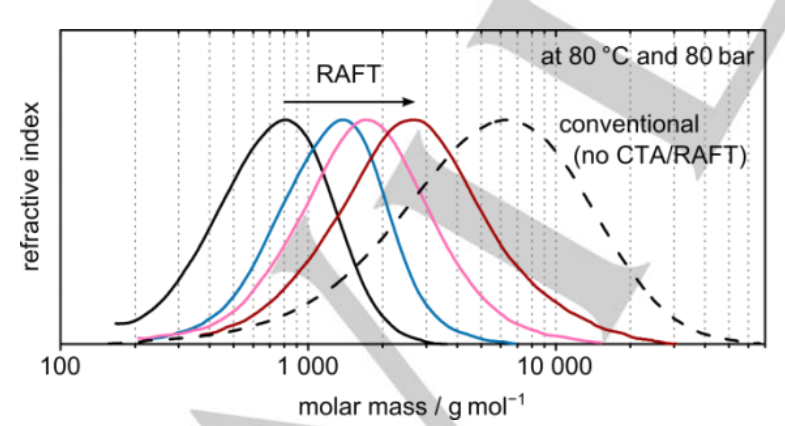

Figure 5. MMDs of PE produced in a conventional system (no CTA/RAFT) after $4 \mathrm{~h}$ and in the presence of 7 after 2, 4, 7, and $16 \mathrm{~h}$.

The originally well-dispersed suspension of PE particles broke down and the particles agglomerated and stuck to the walls of the reactor. We believe that this effect might be related to a poorer dispersion of PE with the phenoxy-type Z-end-groups from either
6 or 7 in supercritical DMC/ethylene compared to nonsupercritical DMC. If this dispersion state prevents the solvent from effectively accessing and swelling PE in the region of the living chain-ends, they will no longer participate in the reaction phase. As a result, for the rest of the polymerization, PE is no longer produced via a RAFT mechanism but only via a conventional radical polymerization mechanism. During this conventional polymerization, dead PE is generated while the PE chains that feature a RAFT end-group simply remain in the system without further participation in the polymerization. Indeed, ${ }^{1} \mathrm{H}$ NMR still shows RAFT-group-functionalized PE even after chain-growth control has already ceased (cf. Figure $2 \mathrm{~b}$, signal $\mathrm{m}$, with about $77 \%$ of chains that are still living). Polymerizations at pressures that are only slightly higher than 95 bar, namely 100 or 120 bar, already show the presence of a high-molar-mass species for $M_{n}>1000 \mathrm{~g} \mathrm{~mol}^{-1}$ (Figure S2). It should be stated that for polymerizations at 80 bar, the same chain-end transformation was observed as for 200 bar (cf. Figure $2 b$, signals between 2.3 and $2.8 \mathrm{ppm}$ as well as in the aromatic region). This clarifies that the two observed effects of losing chain-end functionality and the occurrence of a conventional radical polymerization do not go hand in hand.

Copolymerizations of ethylene with VAc using aromatic xanthates were also investigated to see whether well-defined poly(ethylene-co-vinyl acetate) (EVA) could be obtained in the absence of the side-fragmentation product. ${ }^{[13]}$ In addition, these systems provide more information on the effect of dispersion/solubility on the formation of high-molar-mass chains. CTA 7 was employed at $70{ }^{\circ} \mathrm{C}$ and 200 bar of ethylene pressure. Instead of $50 \mathrm{~mL}$ of DMC, $38 \mathrm{~mL}$ of DMC together with $12 \mathrm{~mL}$ of VAc (total volume of $50 \mathrm{~mL}$ ) were used, while all other conditions remained unchanged. The polymerization results in Figure 4 (series " $70^{\circ} \mathrm{C}, 200$ bar, with VAc") show good chain-growth control, while the MMDs stay unimodal throughout the whole polymerization process (Figure S3), with no high-molar-mass chains arising from conventional radical polymerization. The EVA product ( ${ }^{1} \mathrm{H}$ NMR analysis showed VAc contents of $\left.10 \mathrm{~mol} \%\right)$ is more soluble in DMC than is PE (e.g., at $80^{\circ} \mathrm{C}$, the EVA was found to be completely soluble in DMC, whereas PE was completely soluble only for molar masses lower than $500 \mathrm{~g} \mathrm{~mol}^{-1}$ and completely insoluble for molar masses higher than $2000 \mathrm{~g} \mathrm{~mol}^{-1}$ ). The EVA is thus also expected to be much more soluble in the supercritical DMC/ethylene mixture than PE. As observed in our earlier work, ${ }^{[13]}{ }^{1} \mathrm{H}$ NMR spectra showed no VAc units next to the $\mathrm{CS}_{2}$ group (i.e., no characteristic signal at about $6.7 \mathrm{ppm}$ ), leaving all chains with an ethylene ultimate unit. Since the CTA-bearing chain-ends were identical to those in the PE systems, loss of end-groups could also occur as for pure PE using 7. The fact that end-group loss occurred without the formation of high molar mass chains highlights that the two phenomena are not related.

\section{Polymerizations with $\mathrm{N}$-aromatic dithiocarbamates}

Polymerizations of ethylene were also conducted with dithiocarbamates $8-12$ at $70{ }^{\circ} \mathrm{C}$ and $80^{\circ} \mathrm{C}$ under the same conditions cited above. Systems with 9 showed a very strong retardation. This behavior is expected as INT with $Z=$ 
dimethylpyrazolyl shows by far the lowest tendency to undergo fragmentation of all the CTAs used in the present work. ${ }^{[26,35]}$ As a result, systems with 9 produced PE only for rather low CTA and high AIBN concentrations ([CTA]:[AIBN] $=0.5: 1$ and $100 \mathrm{mg}$ of AIBN compared to the normal conditions of [CTA]:[AIBN] $=3: 1$ and $50 \mathrm{mg}$ of AIBN). Molar mass and NMR data indicated no participation of 9 in an RDRP process under these conditions and it will therefore not be further discussed. The polymerization results of the other dithiocarbamates at $70{ }^{\circ} \mathrm{C}$ and 200 bar are shown in Figure 6. As for the aromatic xanthates, a pronounced retardation is obtained for all systems. The polymerization rates decrease in the following order: $8>11>10 \approx 12$.

(a)

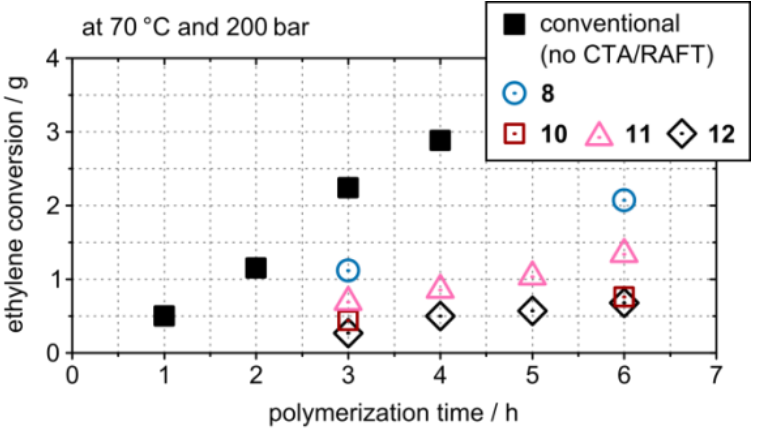

(b)

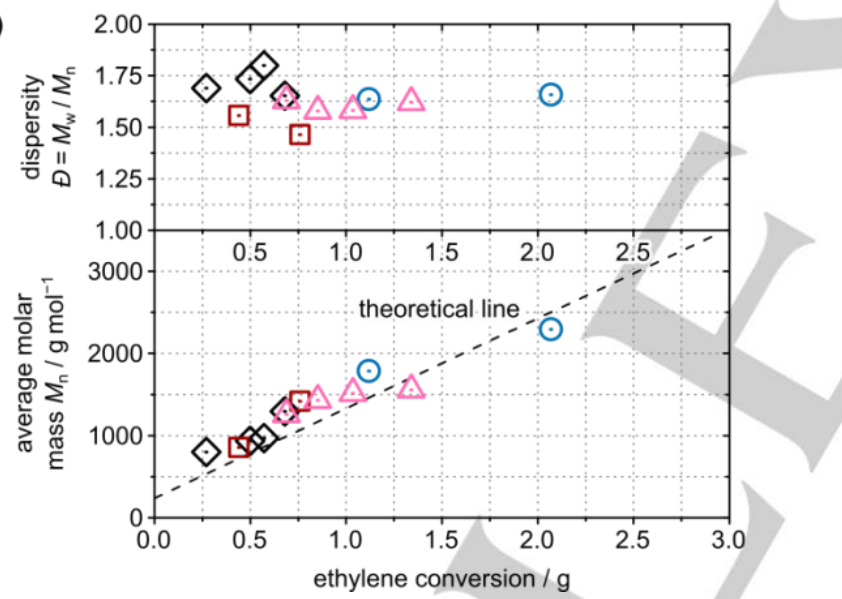

Figure 6. (a) Ethylene conversion versus polymerization time for RAFT systems with dithiocarbamates $\mathbf{8}, \mathbf{1 0}, \mathbf{1 1}$, and $\mathbf{1 2}$ in comparison to the conventional radical polymerization system without a CTA and (b) corresponding molar-mass evolutions. The conventional radical polymerization system yielded PE with $M_{\mathrm{n}}$ values between 8000 and $13000 \mathrm{~g} \mathrm{~mol}^{-1}$ and $\Theta$ values between 2.0 and 3.7 .

The difference between $\mathbf{8}$ and $\mathbf{1 0}$ (identical R-group, different Zgroup) might indicate a higher stabilization of INT• by the Z-group

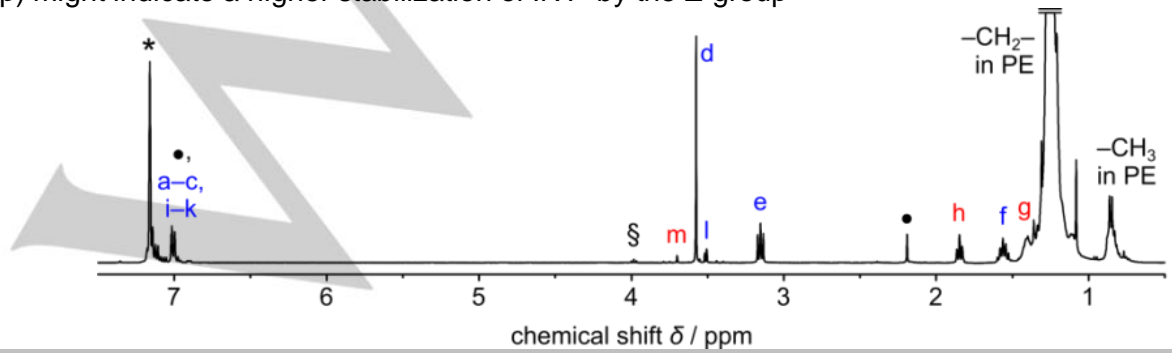

of $10 \mathrm{and} /$ or a higher reactivity of $\mathbf{1 0}$ with $\mathrm{PE} \cdot$ compared to $\mathbf{8}$. The trend of $\mathbf{1 1}>\mathbf{1 0} \approx \mathbf{1 2}$ (identical Z-group, different R-group) might stem from different abilities of the released radical $R^{*}$ to (re)initiate another PE chain. All systems show very good agreement with the theoretically expected $M_{n}$ values, while the obtained $\boxminus$ values are rather constant between 1.4 and 1.8. In contrast to the aromatic xanthate systems, MMDs stay unimodal throughout the entire polymerizations up to $M_{\mathrm{n}}$ much greater than $1000 \mathrm{~g} \mathrm{~mol}^{-1}$, suggesting that the described dispersion effect is less significant for dithiocarbamates. Examples of the MMD of PE from 11 are presented in Figure S7. More importantly, the loss of chain-ends is minor for both $\mathbf{8}$ and $\mathbf{1 0}$. As was the case with the aromatic xanthates, no sign of side fragmentation was present. However, in contrast to the xanthates, the ${ }^{1} \mathrm{H}$ NMR signals between $2.3 \mathrm{ppm}$ and $2.8 \mathrm{ppm}$ were very weak to the point of being difficult to detect for PE produced from $\mathbf{8}$ or $\mathbf{1 0}$. The intensity ratio between the signals of the protons neighboring the $\mathrm{CS}_{2}$ unit and those neighboring the $\mathrm{CN}$ of the R-group stayed constant and close to unity during all polymerizations, indicating no significant loss of chain-end functionality. Figure 7 shows an example of a spectrum of $\mathrm{PE}$ from 8 (after $6 \mathrm{~h}$ of polymerization) with the corresponding respective signals $d / e$ and $h$. In contrast to 8 and 10, the quantification of chain-end functionality is not possible for either $\mathbf{1 1}$ or $\mathbf{1 2}$ as the signals of the protons at the respective R-groups are superimposed by either the $-\mathrm{CH}_{2}-$ or the $-\mathrm{CH}_{3}$ units of PE. Nevertheless, the chain-end functionality of PE from either $\mathbf{1 1}$ or 12 is expected to be similar to the one of PE from 10, because a potential chain-end degradation would happen at the $\mathrm{CS}_{2}$ endgroup, which is identical for 10,11 , and 12 . Still, the decomposition signals between $2.3 \mathrm{ppm}$ and $2.8 \mathrm{ppm}$ are slightly more intense in the case of $\mathbf{1 1}$ and $\mathbf{1 2}$ compared to $\mathbf{1 0}$, so that an impact of the R-group cannot be ruled out at the moment. The systems with $\mathbf{8}$ and $\mathbf{1 0}$ are indeed the first RAFT polymerizations of ethylene that do not suffer from a loss of chain-ends and thus show high chain-end functionality. Looking at the Z-groups of the dithiocarbamates, one might intuitively reason that side fragmentation could happen through the release of the ${ }^{\circ} \mathrm{CH}_{3}$ radical just as for $\mathbf{5}$. However, since this is not observed, the formation of the corresponding dead polymer bearing a $\mathrm{C}=\mathrm{N}$ double bond or the formation of following products is arguably not very favorable.

Polymerizations at $80^{\circ} \mathrm{C}$ (see Figure 8) led to higher ethylene conversion, and thus $M_{\mathrm{n}}$, and all trends already described for $70{ }^{\circ} \mathrm{C}$ were observed. Values of $M_{\mathrm{n}}$ lower than the theoretical values can be observed for higher ethylene conversion obtained with 8. This phenomenon was also observed in our earlier works and was attributed to the inevitable irreversible termination of PE' as well as continuous initiation of new chains by AIBN. ${ }^{[14]}$ All investigated dithiocarbamates are solid at room temperature and therefore remain in the polymeric product after the evaporation of<smiles>CN(C(=S)SCC(C)(C)CCCC(C)(C)CCC#N)c1ccccc1</smiles>

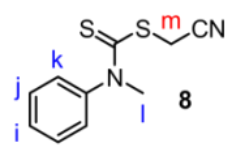


the solvent when not fully consumed during the polymerization. This conveniently allowed us to quantify how quickly a given CTA is consumed in the pre-equilibrium (Scheme 1a).

Figure 7. ${ }^{1} \mathrm{H}$ NMR spectrum of PE synthesized in the presence of 8 (cf. Figure 7, after $6 \mathrm{~h}$ ) and remaining 8 . The end group $-\mathrm{CH}_{3}$ stems from intramolecular chain transfer inherent in ethylene radical polymerization. *NMR solvent benzene, stransfer to the polymerization solvent DMC, "collecting solvent toluene.

In Figure 7 for example, integration of the signals $\mathrm{d}$, e, and $\mathrm{h}$ results in about $92 \%$ of consumed CTA 8 when compared to the signals $\mathrm{I}$ and $\mathrm{m}$. Of all the investigated dithiocarbamates in the present work, 8 shows the slowest consumption with about $71 \%$ after a PE yield of $1.1 \mathrm{~g}$ and $92 \%$ after $2.1 \mathrm{~g}$ at $70{ }^{\circ} \mathrm{C}$.

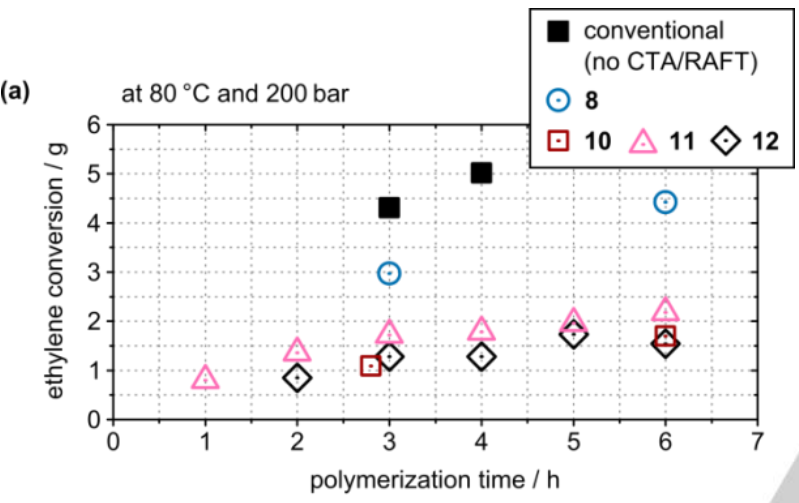

(b)

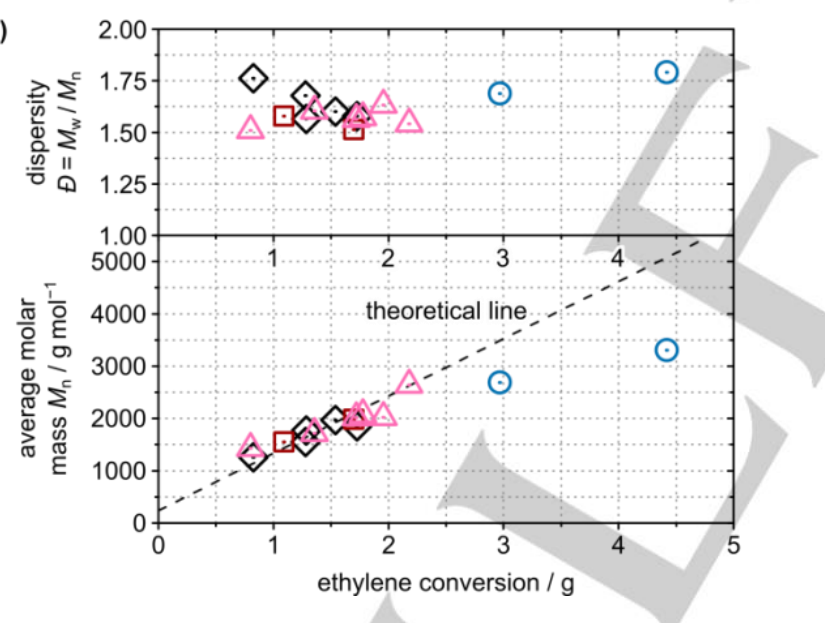

Figure 8. (a) Ethylene conversion versus polymerization time for RAFT systems with dithiocarbamates $8,10,11$, and 12 in comparison to the conventional radical polymerization system without a CTA and (b) corresponding molar-mass evolutions.

8 is consumed about three times more slowly than 10 , which shows about $74 \%$ after $0.4 \mathrm{~g}$ and $92 \%$ after $0.8 \mathrm{~g}$. As 8 and 10 have the same R-group, this indicates that the pyridyl moiety of the Z-group significantly increases the reactivity of the CTA toward $\mathrm{PE} \cdot$ compared with a phenyl moiety. As a result, faster addition of $\mathrm{PE}^{\cdot}$ is also expected during the DT main equilibrium and might lead to a generally better chain-growth control with the pyridyl moiety. By far the fastest consumption of all dithiocarbamates is that of 12 , with about $95 \%$ after $0.3 \mathrm{~g}$ and
$97 \%$ after $0.5 \mathrm{~g}$ at $70{ }^{\circ} \mathrm{C}$. This is explained by the tertiary R-group of 12 being more readily released than the primary one of 10 after the addition of $\mathrm{PE}^{\cdot}$ in the pre-equilibrium. It should be noted that all dithiocarbamates bearing a pyridyl moiety show more or less the same quality in terms of chain-growth control. This is reasonable, as the control of the polymerization basically depends on the frequency of the DT between two PE chains, as long as the CTA has an R-group that is at least equally likely to be released as PE: This is the case for all of the dithiocarbamates used in the current study.

\section{Conclusion}

By employing dithiocarbamate CTAs, we have achieved the first RAFT polymerizations of ethylene that do not suffer from a significant loss of chain-end functionality. The use of aromatic Zgroups suppressed the previously observed side-fragmentation reaction for both xanthate- and dithiocarbamate-controlled ethylene polymerizations. Unprecedentedly low $€$ values (down to 1.2) are still obtained for the aromatic xanthates, underlining what is in principle the high activation-deactivation frequency of $P E$. Loss of chain-end functionality was nevertheless observed for the aromatic xanthates through a different mechanism which is not yet entirely resolved; the possible contribution of crosstermination presents another interesting avenue to explore in the world of RAFT polymerization. The detrimental impact of a supercritical DMC/ethylene phase for polymerizations performed at 200 bars with aromatic xanthates could be circumvented by using ethylene pressures lower than 90 bars.

The presented data help to make a good choice of both polymerization conditions and which CTAs to use when producing (block) copolymers based on ethylene. ${ }^{[36]}$ The results also allow theoretical calculations to compare the substituent effect on the thermodynamics of the radical intermediate and the kinetics of fragmentation. Both topics are already being explored in our laboratory and will be the focus of forthcoming papers.

\section{Acknowledgements}

V.M. and F.D. acknowledge the funding from ANR (Agence Nationale de la Recherche) for the project PolarOBC ANR-15CE07-0015. The authors are grateful to Dr. Lionel Bosco for discussions on the fate of the intermediate radicals. Drs. Timothy McKenna and Samuel Pearson are thanked for very fruitful discussions on the manuscript. 
Keywords: polymerization $\cdot$ radicals $\bullet$ ethylene $\cdot$ reversible addition-fragmentation chain transfer (RAFT) • aryl xanthates • dithiocarbamates

[1] A. D. Jenkins, R. G. Jones, G. Moad, Pure Appl. Chem. 2009, 82, 483491.

[2] M. Destarac, Macromol. React. Eng. 2010, 4, 165-179.

[3] M. Destarac, Polym. Chem. 2018, 9, 4947-4967.

[4] M. Guerre, B. Campagne, O. Gimello, K. Parra, B. Ameduri, V. Ladmiral, Macromolecules 2015, 48, 7810-7822.

[5] S. Banerjee, V. Ladmiral, A. Debuigne, C. Detrembleur, R. Poli, B. Améduri, Angew. Chem. Int. Ed. 2018, 57, 2934-2937.

[6] C. M. R. Abreu, A. C. Fonseca, N. M. P. Rocha, J. T. Guthrie, A. C. Serra, J. F. J. Coelho, Prog. Polym. Sci. 2018, 87, 34-69.

[7] E. Grau, J.-P. Broyer, C. Boisson, R. Spitz, V. Monteil, Phys. Chem. Chem. Phys. 2010, 12, 11665-11669.

[8] J. Nicolas, Y. Guillaneuf, C. Lefay, D. Bertin, D. Gigmes, B. Charleux, Prog. Polym. Sci. 2013, 38, 63-235.

[9] K. Matyjaszewski, Macromolecules 2012, 45, 4015-4039.

[10] A. Anastasaki, V. Nikolaou, G. Nurumbetov, P. Wilson, K. Kempe, J. F. Quinn, T. P. Davis, M. R. Whittaker, D. M. Haddleton, Chem. Rev. 2016, 116, 835-877.

[11] R. Poli, S. M. W. Rahaman, V. Ladmiral, B. Ameduri, J. Organomet. Chem. 2018, 864, 12-18.

[12] C. Fliedel, R. Poli, J. Organomet. Chem. 2019, 880, 241-252.

[13] C. Dommanget, F. D'Agosto, V. Monteil, Angew. Chem. Int. Ed. 2014 , 53, 6683-6686.

[14] Y. Nakamura, B. Ebeling, A. Wolpers, V. Monteil, F. D'Agosto, S. Yamago, Angew. Chem. Int. Ed. 2018, 57, 305-309.

[15] E. Grau, J.-P. Broyer, C. Boisson, R. Spitz, V. Monteil, Macromolecules 2009, 42, 7279-7281.

[16] E. Grau, J.-P. Broyer, C. Boisson, R. Spitz, V. Monteil, Polym. Chem. 2011, 2, 2328-2333.

[17] D. H. R. Barton, D. Crich, A. Löbberding, S. Z. Zard, Tetrahedron 1986 42, 2329-2338.

[18] M. L. Coote, L. Radom, Macromolecules 2004, 37, 590-596.

[19] Q.-B. Chen, T.-Y. Zeng, L. Xia, Z. Zhang, C.-Y. Hong, G. Zou, Y.-Z. You, Chem. Commun. 2017, 53, 10780-10783.

[20] M. H. Stenzel, L. Cummins, G. E. Roberts, T. P. Davis, P. Vana, C Barner-Kowollik, Macromol. Chem. Phys. 2003, 204, 1160-1168.

[21] K. Chen, N. Grant, L. Liang, H. Zhang, B. Tan, Macromolecules 2010, 43, 9355-9364.

[22] C. A. Bell, G. G. Hedir, R. K. O'Reilly, A. P. Dove, Polym. Chem. 2015, 6, 7447-7454.

[23] C. Barner-Kowollik, Handbook of RAFT Polymerization; Wiley-VCH Verlag GmbH \& Co. KGaA: Weinheim, 2008

[24] J. Chiefari, R. T. A. Mayadunne, C. L. Moad, G. Moad, E. Rizzardo, A. Postma, S. H. Thang, Macromolecules 2003, 36, 2273-2283.

[25] M. Benaglia, J. Chiefari, Y. K. Chong, G. Moad, E. Rizzardo, S. H. Thang, J. Am. Chem. Soc. 2009, 131, 6914-6915.

[26] J. Gardiner, I. Martinez-Botella, J. Tsanaktsidis, G. Moad, Polym. Chem. 2016, 7, 481-492.

[27] J. Mazzolini, I. Mokthari, R. Briquel, O. Boyron, F. Delolme, V. Monteil, D. Bertin, D. Gigmes, F. D'Agosto, C. Boisson, Macromolecules 2010 43, 7495-7503.

[28] M. L. Coote, L. Radom, J. Am. Chem. Soc. 2003, 125, 1490-1491.

[29] G. Moad, Macromol. Chem. Phys. 2014, 215, 9-26.

[30] N. De Rybel, P. H. M. Van Steenberge, M.-F. Reyniers, C. BarnerKowollik, D. R. D'hooge, G. B. Marin, Macromol. Theory Simul. 2017, 26 , 1600048.

[31] H. Staudinger, G. Rathsam, Helv. Chim. Acta 1922, 5, 645-655.

[32] E. Márquez, J. R. Mora, T. Cordova, G. Chuchani, J. Phys. Chem. A 2009, 113, 2600-2606.

[33] D. Konkolewicz, B. S. Hawkett, A. Gray-Weale, S. Perrier, J. Polym. Sci. Pol. Chem. 2009, 47, 3455-3466.
[34] S. R. S. Ting, T. P. Davis, P. B. Zetterlund, Macromolecules 2011, 44, 4187-4193.

[35] J. Gardiner, I. Martinez-Botella, T. M. Kohl, J. Krstina, G. Moad, J. H. Tyrell, M. L. Coote, J. Tsanaktsidis, Polym. Int. 2017, 66, 1438-1447.

[36] C. J. Kay, P. D. Goring, C. A. Burnett, B. Hornby, K. Lewtas, S. Morris C. Morton, T. McNally, G. W. Theaker, C. Waterson, P. M. Wright, P. Scott, J. Am. Chem. Soc. 2018, 140, 13921-13934.

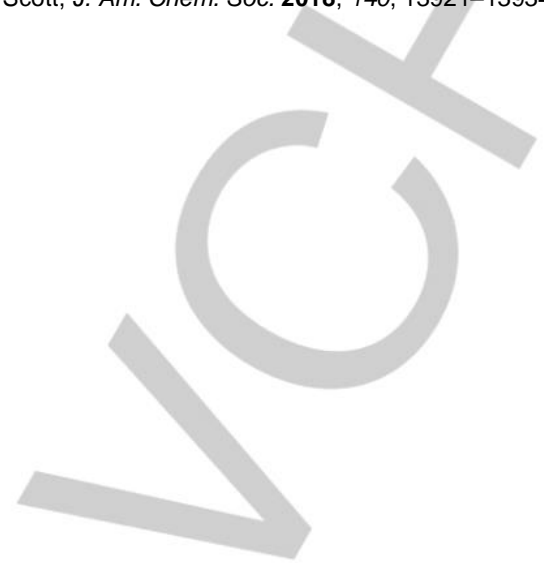




\section{RESEARCH ARTICLE}

Controlled radical polymerization of ethylene was conducted through RAFT using aryldithiocarbonates or aryldithiocarbamates as controlling agents. The use of dithiocarbamates led to well-defined polyethylene chains in absence of detectable side reactions.

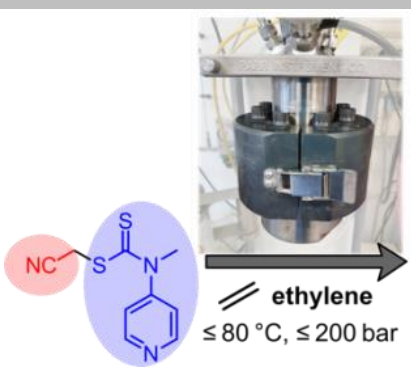

RAFT

$\nabla$ no side fragmentation

『 high chain-end fidelity

『 well-defined polyethylene

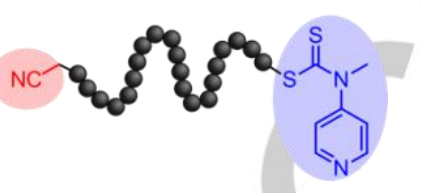

A. Wolpers, C. Bergerbit, B. Ebeling, F. D'Agosto, * V. Monteil*

Page No. - Page No.

Aromatic xanthates and dithiocarbamates for the polymerization of ethylene through reversible addition-fragmentation chain transfer (RAFT) 